\title{
Artquis
}




\section{Construcción sensible del paisaje}

Msc. Miguel Braceli, Arquitecto

Invitado internacional

Universidad Central de Venezuela

http://www.miguelbraceli.com/

miguelbraceli@gmail.com

Recibido: mayo del 2016

Aceptado: junio del 2016

Artquis

Reseña 


\section{Resumen}

La obra de Miguel Braceli muestra una reflexión sobre el espacio que trasciende las fronteras de lo que usualmente se entiende como espacio arquitectónico. El registro fotográfico de las instalaciones efímeras que se incluye en esta reseña revela un trabajo sobre el territorio y el paisaje que desmonta los principios de estabilidad, permanencia y robustez que se le asocian al quehacer arquitectónico. En este sentido, la obra de Miguel Braceli se considera relevante para la discusión sobre a la dimensión temporal del espacio y las funciones lúdicas y experimentales de este tipo de proyecto sobre el espacio.

Palabras clave: arte efímero; espacio temporal; paisaje; territorio.

\section{Abstract}

The work of Miguel Braceli demonstrates a consideration about space that transcends the boundaries of what is usually understood as architectural space. The photographic record of ephemeral installations included in this review reveals a work about the territory and landscape that dismantles the principles of stability, permanence and robustness that are associated with the architectural work. In this sense, the work of Miguel Braceli is considered relevant to the discussion around the temporal dimension of space and playful and experimental features of this type of project on space.

Keywords: ephemeral art; temporary space; landscape; territory. 


\title{
Construcción sensible del paisaje
}

\author{
Miguel Braceli ${ }^{1}$
}

El trabajo de Miguel Braceli consiste en intervenciones efímeras realizadas desde la participación colectiva para construir imágenes sensibles al paisaje en que se insertan, modificándolo temporalmente y absorbiendo su transformación.

Las obras intervienen el paisaje y el mismo paisaje interviene las obras a posteriori. Su investigación intenta reconocer estas relaciones de transacción, para ser develadas en trabajos vivos que hacen del cambio su sustancia constitutiva. Son proyectos en diálogo con su transformación, ensayos materiales y humanos sensibles al tiempo. Metáforas que se expresan en su propio transcurrir. Son exploraciones donde la composición no es un producto estable, en sus formas la estética se desenvuelve en diálogo con el cambio y su misma afectación.

El arte hoy se acerca a la sociedad en un modo distinto, trata de restablecer las relaciones con la vida más allá de su representación. Se introduce en lo cotidiano, dialoga con ello hasta hacerlo parte de sí. Existe una relación de intercambio entre la obra y la vida a partir de una mutua transformación. Las obras nacen de reconocer los fenómenos que se desarrollan en el paisaje, a la vez que involucran a las personas para intervenir en su creación.

El paisaje es el espacio recreado para plasmarse en la experiencia que la fotografía retrata. En el exterior, los paisajes son alterados con nuevos contenidos programáticos para develar una estética distinta, cargada de significados que nacen de un contexto originante. En el interior los paisajes se recrean en pequeños formatos, introduciendo sus atributos, potenciando su capacidad para generar efectos sobre la misma obra o desde sus relaciones con el espectador. El paisaje como construcción temporal a partir de sus relaciones con la vida es el centro de todas las exploraciones formales y conceptuales en las que cada una de las obras converge.

\footnotetext{
1 Miguel Braceli es Arquitecto por la Universidad Central de Venezuela (2007) y Máster en Diseño Arquitectónico por la Universidad Central de Venezuela (2013). Ha desarrollado intervenciones efímeras de gran formato sobre el espacio público en Venezuela, Argentina, Colombia, Costa Rica y Chile. Es profesor en el área de diseño y pertenece al Centro de Estudio del Espacio Arquitectónico de Facultad de Arquitectura y Urbanismo de la Universidad Central de Venezuela desde el año 2008 y profesor del Diplomado de Arte Contemporáneo de la Sala Mendoza junto a la Universidad Metropolitana. Coordinador del Taller X de la FAU UCV. Director y fundador de Proyecto Colectivo, un espacio de experimentación desde donde ha venido desarrollando su trabajo para la producción de obras en el espacio público a través de modelos participativos.
} 

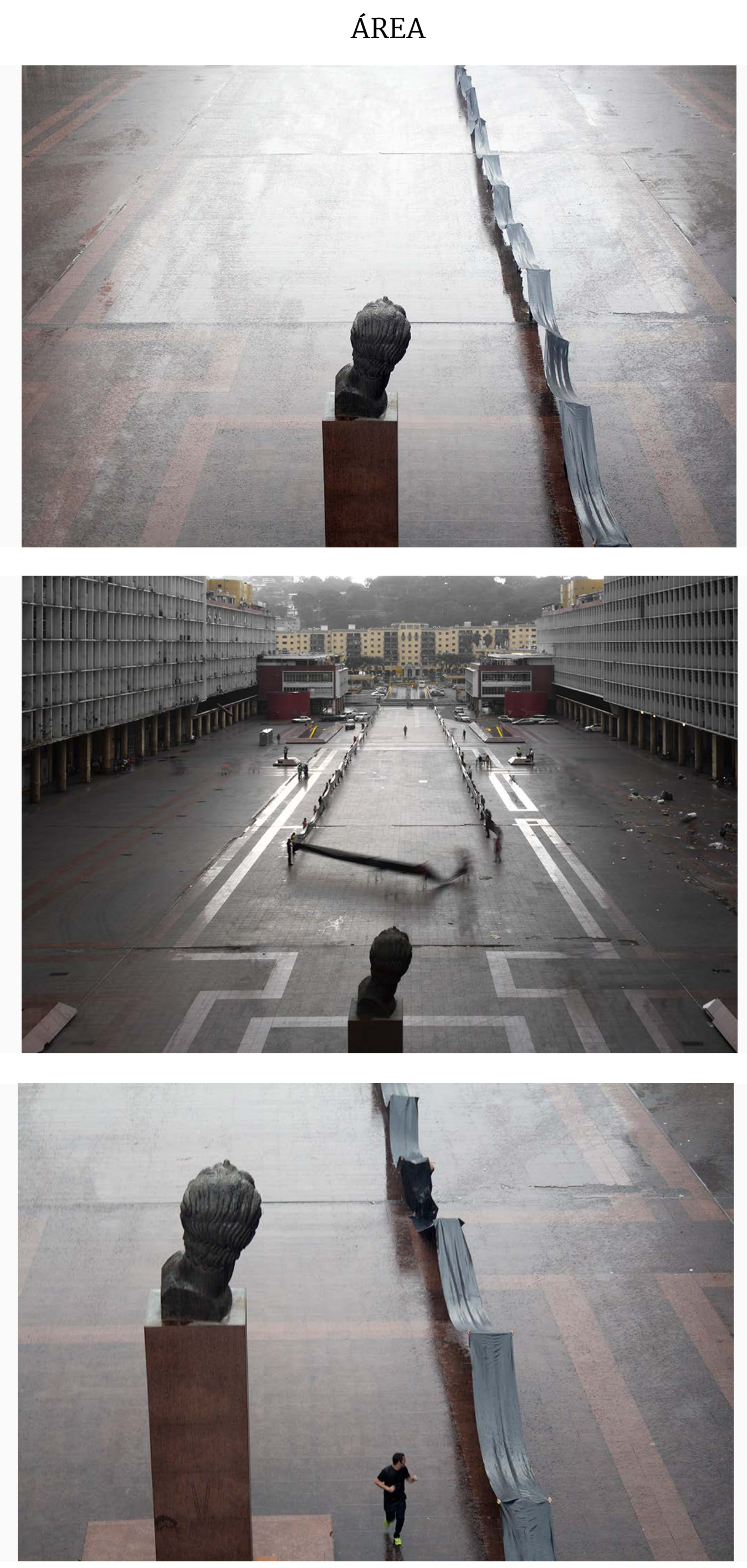

ÁREA. (2014). Caracas, Venezuela. El proyecto se desarrolló con la ocupación efímera de Plaza Caracas en un performance de participación colectiva enfocada a medir el vacío de este espacio urbano y dibujar sus formas con múltiples cuerpos en movimiento. "Área" es el término cuantitativo para evidenciar el contenido cualitativo de las cargas sociales, políticas y culturales que los espacios públicos soportan. Son estos contenidos los límites generadores de ciudades paralelas producto de la polarización. Fronteras intangibles que esta obra quiso desdibujar a través de la construcción de una nueva área común en el centro de la ciudad. 


\section{INMATERIALES}

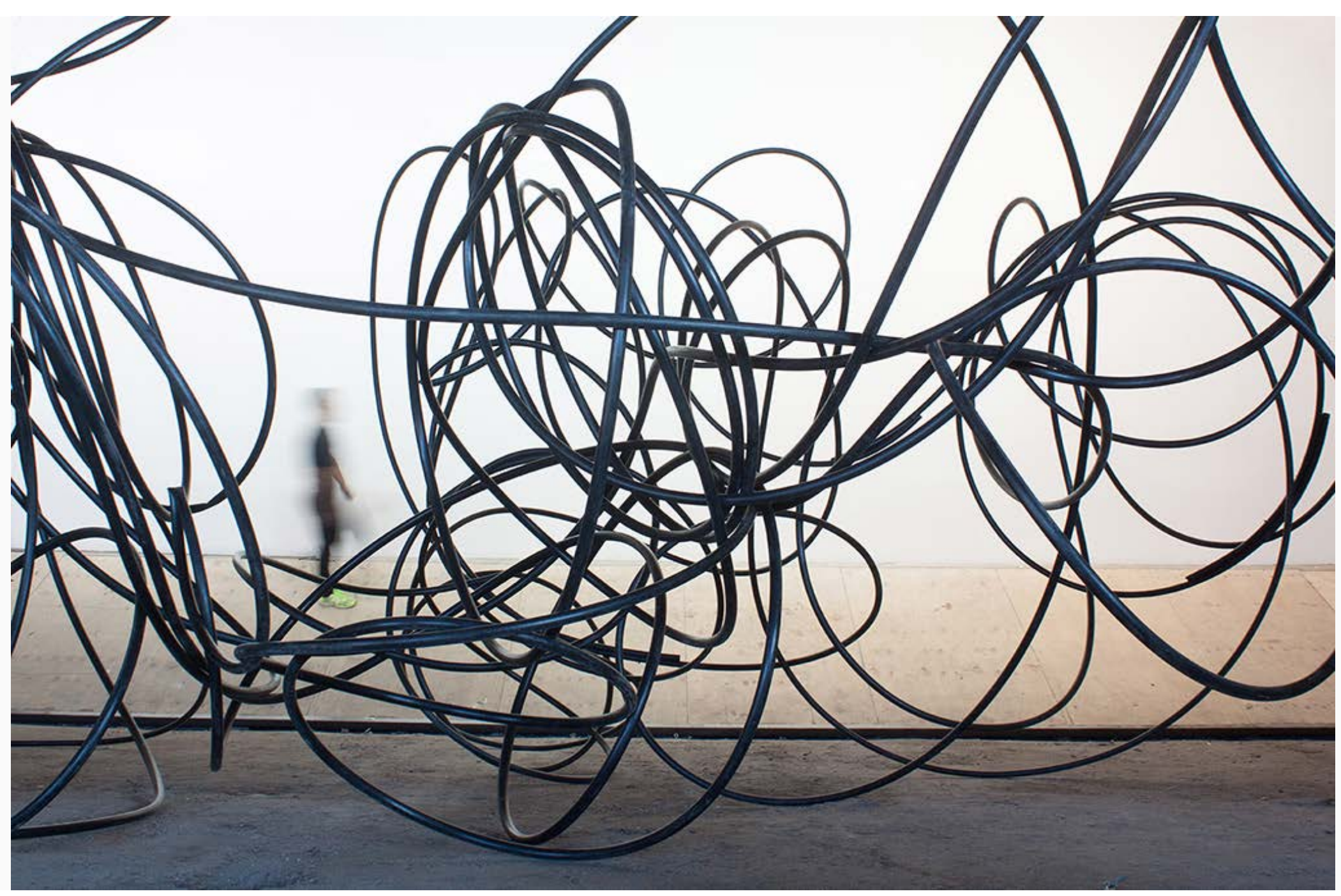

INMATERIALES (2014). Intervención participativa en el Museo de la Memoria y de los Derechos Humanos, Santiago de Chile. Taller con estudiantes de arquitectura y performance La pieza es un tejido cuyas formas fueron cambiando con la acción de los participantes. El acto de la construcción y la destrucción era una forma progresiva de moldear el trabajo. Este resultado fue una consecuencia de la relación entre el material y el cuerpo. de Chile. En la obra se tejen y reescriben los 30 puntos de la Declaración Universal de los Derechos Humanos presentes en las paredes exteriores del museo. El accionar sobre estos espacios fue una estrategia para poner en evidenciar la ausencia de estos textos cuando se convierten en monumento. 


\section{MANANTIAL}

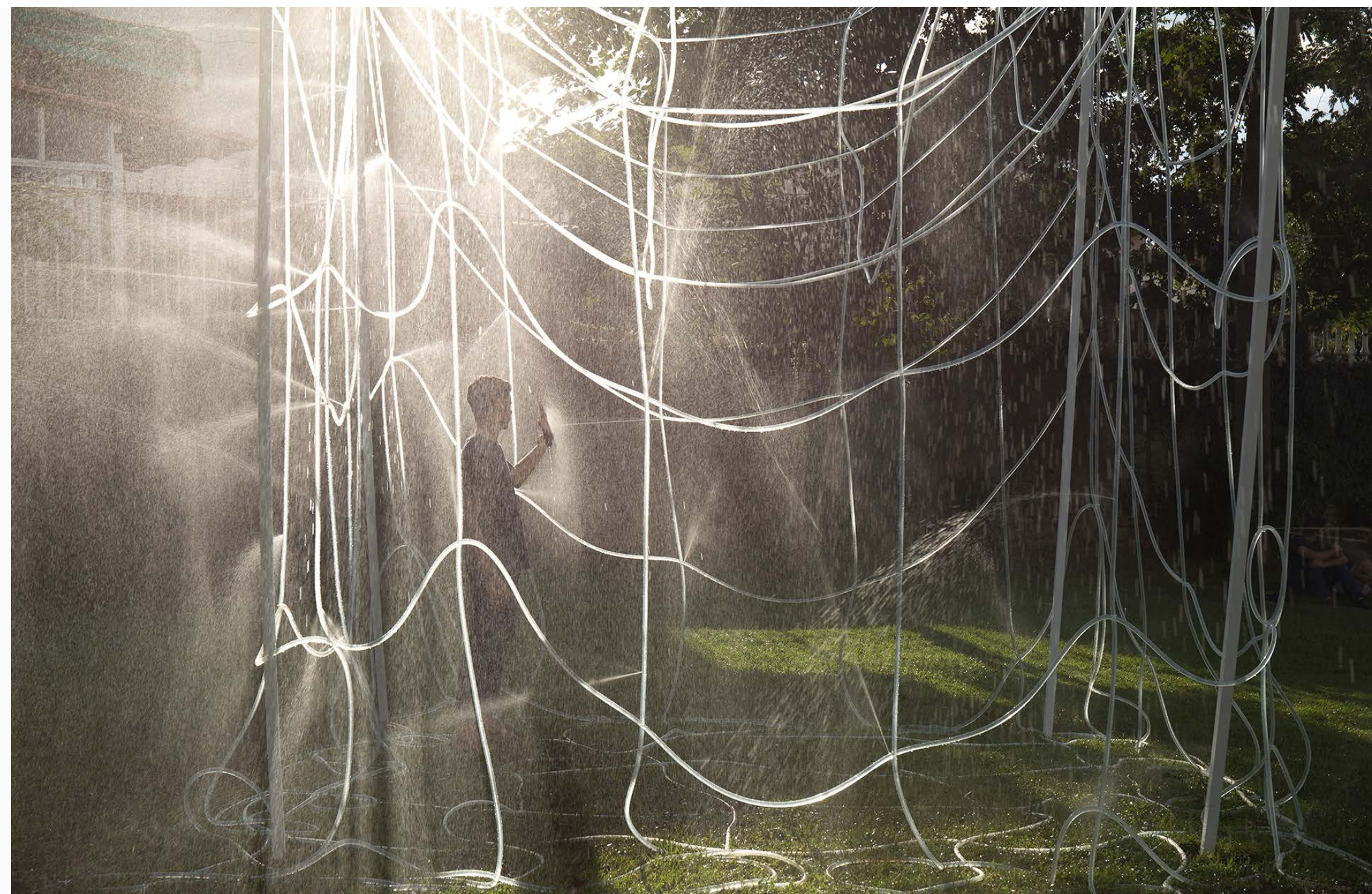

MANANTIAL. (2015) Hacienda La Trinidad Parque Cultural, Caracas, Venezuela. Intervención efímera en un jardín y parque cultural. Es un espacio que recolecta agua natural desde un manantial para retornarla al jardín a través de una instalación interactiva. Esta pieza busca construir desde la materia intangible para producir espacios vivos a través del juego. 


\section{TRASLACIONES}
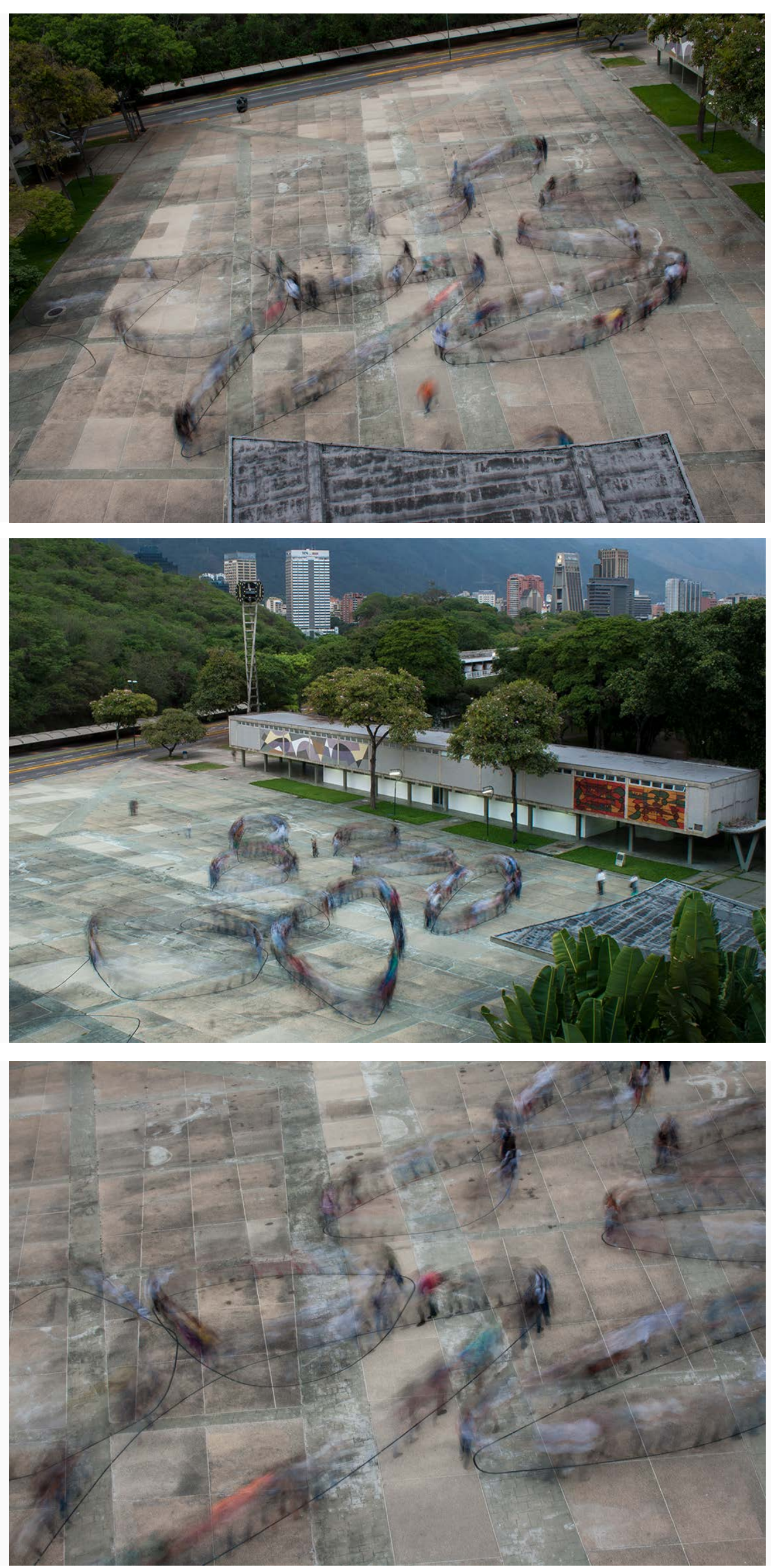

TRASLACIONES. (2014) Caracas, Venezuela. Las Nubes de Calder en el Aula Magna constituyen una de las obras más significativas de la relación arte y arquitectura presente en la Ciudad Universitaria de Caracas. "Traslaciones" consistió en un performance de participación colectiva para sacar las Nubes al campus universitario y redibujarlas a través del desplazamiento de las personas. Es una obra que intenta construir volúmenes sin materia, hacer de lo efímero un estado permanente en el registro como obra. Esta intervención se hace a los 60 años de haber sido inaugurada el Aula Magna, en un contexto social, político y económico diametralmente distinto. Es por ello que sus únicos elementos fueron las personas que hacen vida en la Universidad. 


\section{CATAMARCA}
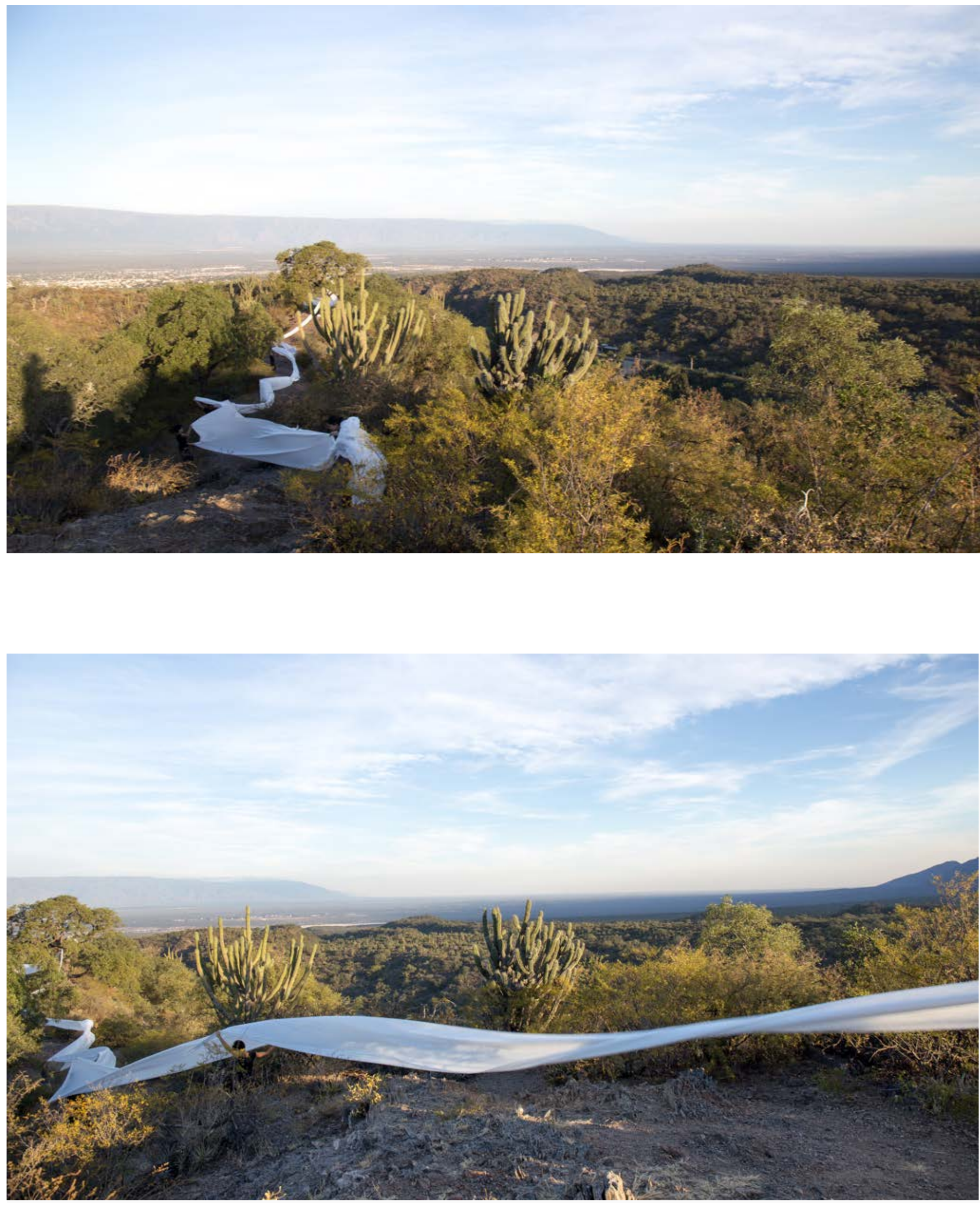

CATAMARCA. (2015) Argentina. Intervención participativa en el Valle de Catamarca, dibujando las coreotopías de sus bosques. La obra se planteó como un ensayo sobre el tránsito y la levedad para la construcción de formas con la participación de las comunidades locales. El performance es un medio para dibujar sobre el paisaje, donde el mismo paisaje es capaz de transformar la obra a través de sus fenómenos y el tiempo. 


\section{CATAMARCA}
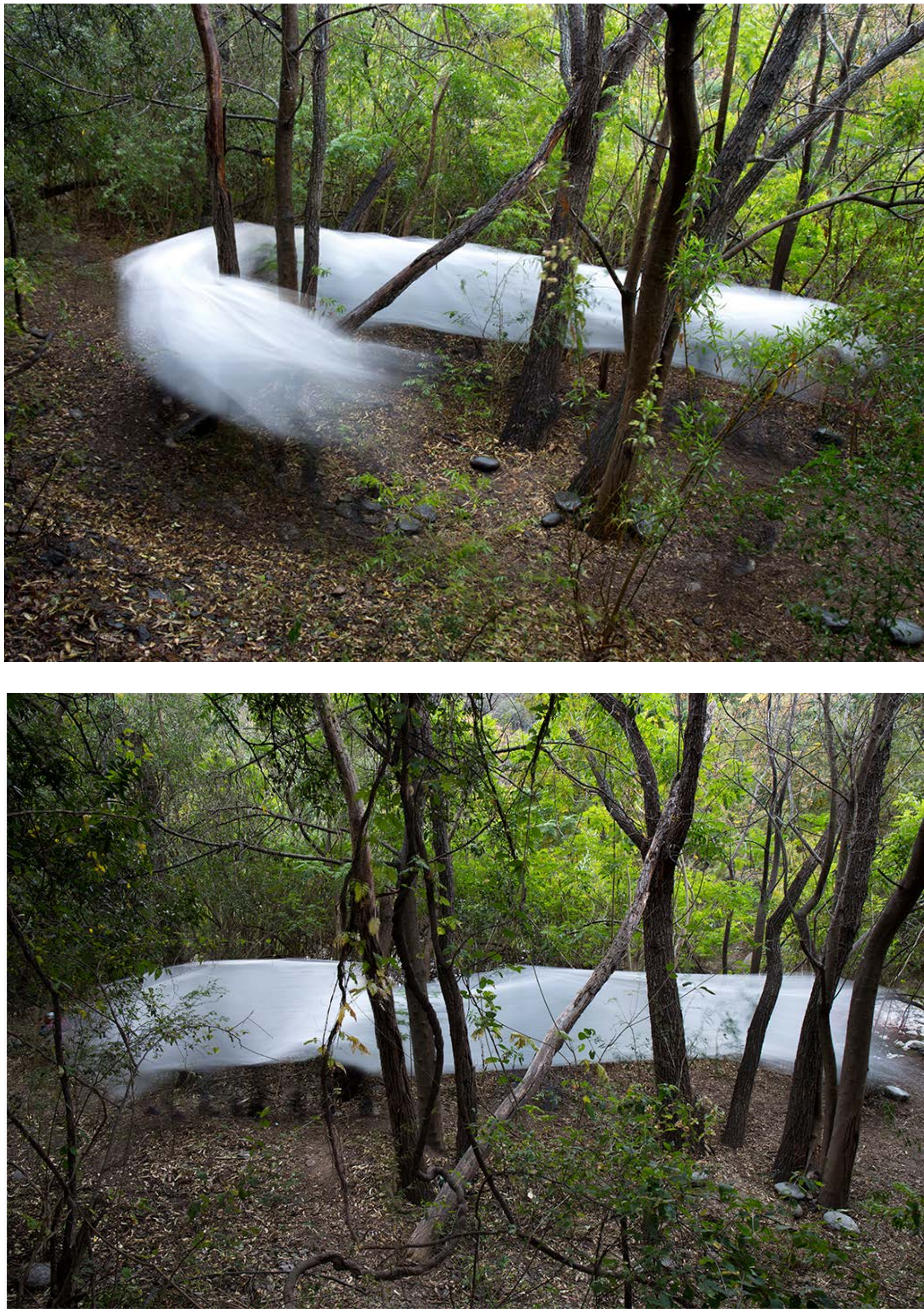


\section{LA NUBE}
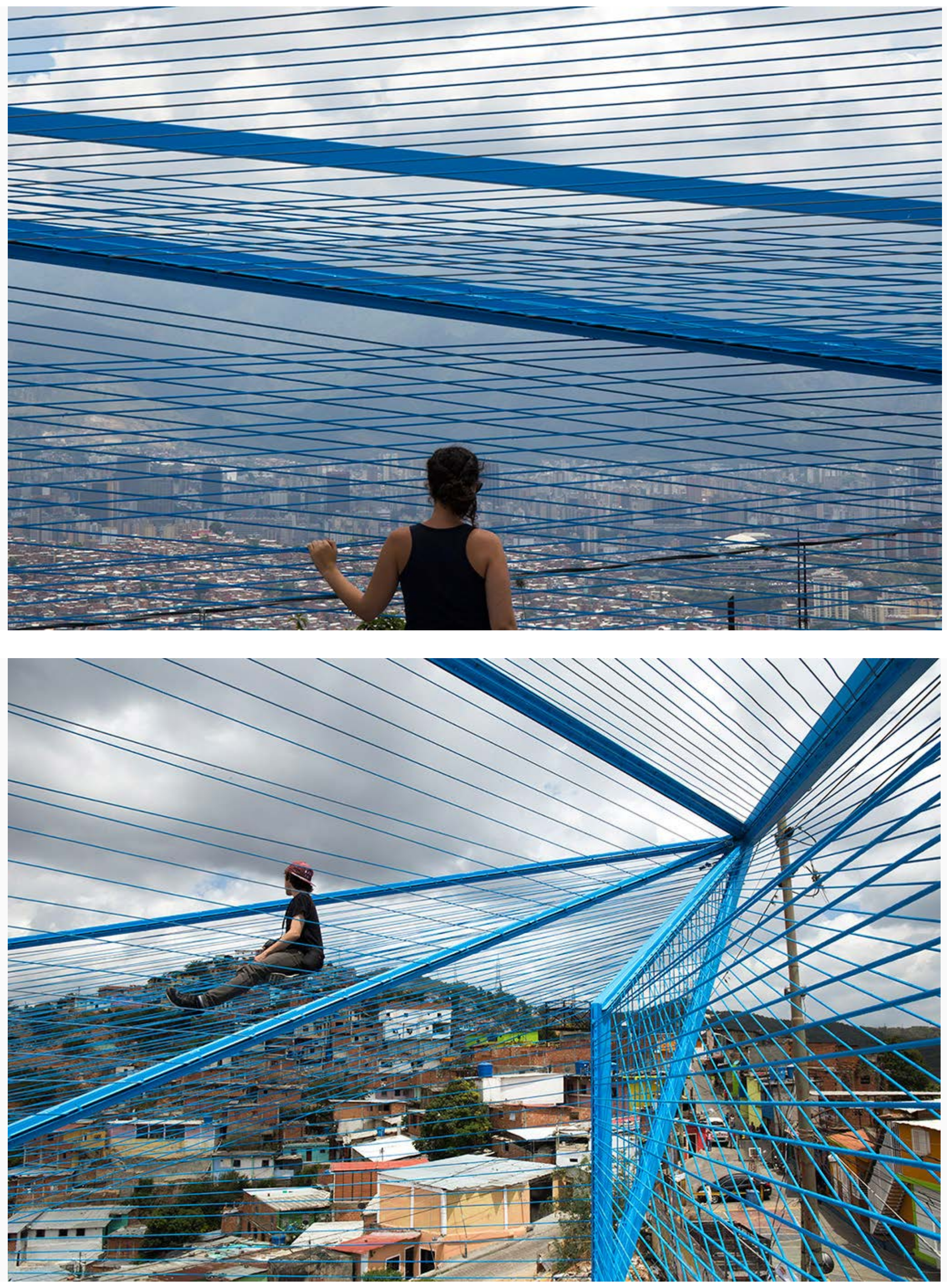

LA NUBE. (2015) Caracas, Venezuela. Instalación permanente en un asentamiento informal de Caracas. La pieza es un espacio lúdico para la contemplación. Es un hito en el paisaje y un lugar para contemplar el paisaje desde una superficie lúdica en suspensión. La Nube fue construida a partir de un proceso participativo trabajando con personas de la comunidad a la que pertenece esta pieza. 
Este artículo forma parte de:

\section{REVISTARQUIS}

Para más información, artículos, e instructivo de publicación, visite:

www.arquis.ucr.ac.cr/revistarquis.html 